\title{
Impact of the Salmonella status of market-age pigs and the pre-slaughter process on Salmonella caecal contamination at slaughter
}

\author{
Pierre-Alexandre BELEIL ${ }^{\mathrm{a} *}$, Claire CHAUVIN ${ }^{\mathrm{a}}$, Karine PROUX ${ }^{\mathrm{a}}$, \\ François MADEC ${ }^{\mathrm{a}}$, Philippe FRAVALO ${ }^{\mathrm{a}}$, Ahmadou AlIOUM ${ }^{\mathrm{b}}$ \\ a AFSSA, French Agency for Food Safety, Pig and Poultry Veterinary Research Laboratory, \\ Zoopôle, BP 53, 22440 Ploufragan, France \\ b ISPED, Institut de Santé Publique, d'Épidémiologie et de Développement, \\ Université Victor Segalen Bordeaux 2, 146 rue Léo Saignat, 33076 Bordeaux Cedex, France
}

(Received 24 November 2003; accepted 20 February 2004)

\begin{abstract}
The aim of this study was to evaluate the impact of the pre-slaughter process on Salmonella caecal contamination of pigs at slaughter. An observational study was carried out in 2001 on 101 conventional farrow-to-finish pig farms. On each farm, one batch of contemporary pigs was followed from the end of the fattening period until slaughter. The Salmonella bacteriological status of the batches was assessed by environmental samples of faecal material. The serological Salmonella status was obtained on 30 individually identified market-age pigs using an indirect ELISA test. At the slaughterhouse, $25 \mathrm{~g}$ of caecal contents were taken from $10 \mathrm{of}$ the identified pigs. Faecal and caecal material were analysed according to a classical bacteriological method. A questionnaire was designed to obtain information about the type of feeding during the fattening period (dry versus wet), the duration of fasting on the farm before leaving for the slaughterhouse, the duration of transport between the farm and the slaughterhouse, the holding time in lairage at the slaughterhouse and loading and unloading conditions on the farm and at the slaughterhouse. To assess the relationships between these factors and the Salmonella caecal status of the pigs and the batches, two logistic models were fitted at the individual and at the batch level, respectively. The first analysis was performed using a random effects logistic regression model. The second analysis was based on a cumulative logit model with a positive caecal rate classified into three classes as the outcome variable. The results showed that the Salmonella status of market-age pigs assessed on the farm either by serological or bacteriological examinations and the time spent in lairage before slaughtering played a crucial role on caecal contamination. In the light of these results, actions should be considered both on the farm and at the slaughterhouse to decrease the risk of Salmonella contamination of the caecal contents.
\end{abstract}

Salmonella / pigs / pre-harvest process / slaughterhouse

\footnotetext{
* Corresponding author: pierre-alexandre.beloeil@agriculture.gouv.fr

Present address: Ministère de l'agriculture, de l'alimentation, de la pêche et des affaires rurales, Direction générale de l'alimentation, Sous-Direction de la sécurité sanitaire des aliments, 251 rue de Vaugirard, 75732 Paris Cedex 15, France
} 


\section{INTRODUCTION}

Foodborne salmonellosis has been recognized as a major threat to public health. Salmonellosis outbreaks have been associated with the consumption of pork and pork products. Concerns about pork safety have stimulated research along the food chain in an attempt to determine the effects of various pre- and post-harvest processes on the prevalence of Salmonella contamination. Laceration of contaminated digestive tracts at the slaughterhouse is bound to expose the whole carcass and neighbouring carcasses to Salmonella contamination [4]. A reduction of Salmonella intestinal carriage at the pre-harvest level should therefore reduce the risk of contamination at subsequent stages, especially at slaughter.

The pre-harvest process includes onfarm production, fasting and holding before shipment, loading, transportation, unloading and lairage at the slaughterhouse. Pigs may become infected during the rearing period on the farm. Asymptomatic intestinal carriage and intermittent shedding of small numbers of Salmonella characterise subclinically Salmonella-infected pigs [39, 42]. However, from the moment they leave the farm, pigs are exposed on several occasions to a risk of Salmonella contamination. It has been shown that the proportion of pigs contaminated increases between the farm and the slaughterhouse, when the same sampling method is used on the farm and at the slaughterhouse [15]. These observations therefore suggest an impact of the pre-slaughter process. The effect of feed withdrawal on the farm (fasting) before loading is not clear. Some studies have not reported any effect of fasting [23], whereas others have suggested a protective effect of fasting [17] on the Salmonella isolation rate in caecal contents at the slaughterhouse. A transport effect was pointed out more than thirty years ago by Williams and Newell [43] despite the small number of pigs considered $(n=20)$. Subsequent studies have shown that trucks transporting pigs are frequently contaminated by
Salmonella upon arrival at the slaughterhouse [28, 31, 37]. However, the direct role of transport on Salmonella contamination was not clearly demonstrated. Lairage time has also been shown to increase Salmonella shedding before slaughter $[15,16]$.

Many of the studies indicated above were experimental studies. The effects of diverse factors, such as duration of fasting on the farm before loading [17, 23], presence and duration of transport $[16,17]$ and the conditions and duration of holding in lairage $[14,31]$ were measured. To the best of our knowledge, no study has tried to observe the events occurring between the farm and the slaughterhouse in order to assess, without any intervention, the associations between suspected risk factors related to the preslaughter process and Salmonella contamination of caecal contents. Assessment of the impact of pre-slaughter events on Salmonella prevalence is a critical step to develop pathogen reduction strategies.

The objective of this observational study was to evaluate the relative effect on Salmonella caecal carriage of various events occurring between the fattening pens on the farm until the slaughter line. In order to investigate the risk factors for caecal contamination at the slaughterhouse, the results were first analysed individually. A second model was fitted at the batch level in order to identify control points of special interest in terms of Salmonella risk management that must be devised and applied at the batch or farm level.

\section{MATERIALS AND METHODS}

\subsection{Study sample}

The study was carried out in 2001 and involved 101 French farrow-to-finish family pig farms selected among those affiliated to 14 farmer organisations and 8 feed companies. The farms involved in the study had to be confined farrow-to-finish operations of the intensive type and managed 
using the batch procedure (weaning of a group of sows on the same day and age-segregated rearing) and an all-in/all-out hygiene policy for farrowing, post-weaning and fattening sections. The farms were located all over France, but most of them were located in Brittany (80.2\%), where more than 54\% of the national pig herd is located [18]. Since recruitment was not based on random sampling, the general characteristics (herd size, reproductive and growing performances, mortality rate in the different sectors) of the final sample of farms were compared retrospectively with the average values available in broad national and regional (Brittany) databases [18]. Eighteen slaughterhouses, all specialised in pigs, were involved in the study.

\subsection{Study design}

A batch of contemporary finishing pigs housed in the same room was studied on each farm. This will be referred to with the term "batch" in the text. A room was part of a fattening building separated from the rest of the unit by walls and a door and usually containing 80 to 150 finishing pigs housed in 8 to 12 pens. In the selected room, 30 pigs were randomly selected (simple random sampling i.e. with no stratification by pen) and submitted to the survey. The farms were visited by investigators several days before slaughtering in order to assess the bacteriological and serological Salmonella status of the finishing batches studied (cf. Sect. 2.4.1) and to collect data concerning the general characteristics of the rooms studied, such as the dimensions of each pen in the rooms. The batches were then observed at the slaughterhouse, where they were transported and slaughtered according to the plant's routine practices. The loading and slaughtering time schedules for the pigs studied were established by the slaughterhouse department routinely responsible for that task. The investigators were informed of these schedules by the farmers and the investigators were asked to comply with these schedules. At the slaughterhouse, the pigs studied were held in a standard pen, stunned, exsanguinated and processed according to the usual procedures. Caecal contents from a sample of 10 finishing pigs out of the 30 pigs studied were taken by the investigators on the slaughter line. The investigators were veterinarians and technicians from the companies involved or staff from our laboratory. Prior to the survey, a meeting was held with external investigators, who were trained in sampling techniques on the farm and at the slaughterhouse. A handbook detailing data collection procedures was prepared prior to the study and distributed to the investigators.

\subsection{Data collection}

A specific data collection form (available upon request from the corresponding author) related to each step of the pre-harvest process was completed on the day of slaughtering or on the following day by a personal interview with the farmer, the lorry driver and the slaughterhouse employee supervising unloading and lairage. The following data were recorded: time (date and time) of feed withdrawal, characteristics of the specific premises in which slaughter pigs were housed before loading (division in pens, sprinkling pigs with water, cleaning and disinfection before housing pigs), use of a loading platform, time and duration of loading, time and duration of unloading and time of slaughtering.

\subsection{Sample collection}

\subsubsection{On the farm}

The bacteriological Salmonella status of the pens of the finishing room in which the studied pigs were housed was assessed by performing faecal sampling using sterile pairs of gauze socks (Sodibox, La Forêt-Fouesnant, France). The pair of socks consisted of an elastic cotton tube pulled over the investigator's over-boots. While walking all over the surface of the pen, the cotton tubes 
absorbed faecal material. One pair of socks was used per pen except for rooms with only 2 or 3 large pens, in which case 2 or 3 pairs of socks were used in the same wide pen in order to cover approximately the same floor surface with one pair of socks. The distribution of the surfaces sampled per room was described retrospectively. After use, the soiled pair of socks was placed in a sterile plastic bag using a sterile glove. As a precaution against introduction of infected faeces from an adjacent pen, plastic overboots, gloves and other materials were changed between each pen.

In each compartment included in the study, the 30 pigs randomly selected were individually identified with a code written on an ear tag and tattooed on the shoulders. The pen locations were recorded. The selected pigs were bled a few days before slaughter to assess their serological Salmonella status.

\subsubsection{At the slaughterhouse}

At the slaughterhouse, $25 \mathrm{~g}$ of caecal contents were collected from ten pigs identified on the farm. The ten pigs belonged to the first slaughter group from the room followed, containing at least 10 pigs from the 30 identified. On the slaughter line, carcasses were identified by reading the shoulder tattoo and/or the ear tag number. Just after evisceration, the digestive tract was collected and numbered to match the carcass number (tattoo or ear tag). The caecal samples were taken in a specific area within the plant, several minutes after evisceration. A small surface of the distal part of the caecum (approximately $5 \mathrm{~cm}^{2}$ ) was flame sterilised. About $25 \mathrm{~g}$ of caecal contents were collected via a puncture performed in the middle of the sterilised area and were placed in a sterile plastic bag identified with the carcass number. Caecal samples were transported to the laboratory in an icebox on the same day (or by cooled express mail) and processed on the same day or stored cold $\left(4{ }^{\circ} \mathrm{C} \pm 1{ }^{\circ} \mathrm{C}\right)$ overnight before bacteriological examination.

\subsection{Serological examination}

The serological Salmonella status of the pigs was assessed using an indirect ELISA [26]. Salmonella IgG antibodies were detected in serum using a complete ELISA based on LPS from $S$. Typhimurium, Enteritidis, Anatum, Hadar and Infantis [26]. Optical densities were determined by a Dynatech MR5000 plate reader spectrophotometer using 490 and $630 \mathrm{~nm}$ filters as the test and reference filters, respectively. The Calibrated Optical Densities (COD) were calculated as follows:

$$
\begin{aligned}
\mathrm{COD}= & \left(\mathrm{OD}_{\text {sample }}-\mathrm{OD}_{\text {negativecontrol }}\right) / \\
& \left(\mathrm{OD}_{\text {positive control }}-\mathrm{OD}_{\text {negative control }}\right) .
\end{aligned}
$$

Samples with COD $\geq 0.4$ were considered to be positive according to the previously defined cut-off value [26]. ELISA sensitivity and specificity were estimated at $97 \%$ and $94 \%$, respectively by Proux et al. [26].

\subsection{Salmonella isolation and identification}

Environmental pairs of gauze socks and caecal contents were analysed for the presence of Salmonella enterica. Three hundred millilitres of buffered peptoned water (BPW) (AES Laboratoires, Combourg, France) were poured into each plastic bag containing the socks. Twenty five grammes of caecal material were immersed in $225 \mathrm{~mL}$ of BPW. They were incubated for 16 to $20 \mathrm{~h}$ at $37^{\circ} \mathrm{C}$. Following pre-enrichment, selective enrichments were performed on both Modified Semisolid Rappaport Vassiliadis agar (MSRV) (Merck, Nogent-sur-Marne, France) and MüllerKauffmann Tetrathionate Broth (MKTB). These selective media were incubated at $41.5{ }^{\circ} \mathrm{C}$ and $42{ }^{\circ} \mathrm{C}$ for 18 to $20 \mathrm{~h}$, respectively. A delayed 3-day secondary enrichment for MSRV plates was performed in order to increase sensitivity. Plating included streak inoculations from the migrated colonies of MSRV plates onto Rambach agar plates (Humeau, La Chapelle-sur-Erdre, France) and from MKTB onto Xylose-Lysine-Tergitol-4 (XLT4) agar plates. Rambach and 
XLT4 media were both incubated at $37{ }^{\circ} \mathrm{C}$ for $24 \mathrm{~h}$. Two presumptive positive colonies on XLT4 or/and Rambach plates were confirmed by biochemical assays on inoculated Kligler-Hajna medium (AES Laboratoires, Combourg, France) incubated at $37{ }^{\circ} \mathrm{C}$ for $24 \mathrm{~h}$. All isolates were serotyped by agglutination according to the Kauffman-White scheme using Salmonella polyvalent $\mathrm{O}$ and $\mathrm{H}$ antisera (Diagnostics Pasteur, Paris, France).

\subsection{Statistical procedures}

The distribution of variables was described. To exclude a hypothetical measurement bias, the average surfaces sampled by pairs of socks in rooms tested positive and negative were compared by the Student $t$ test and the influence of the number of pairs of socks used on the final status of the room was tested by the Fisher exact test. Outcome and explanatory variables were categorised. The number of categories per variable was limited, so that frequencies of categories were $>10 \%$.

\subsubsection{Definition of variables}

A pig was declared to have the caecal contents contaminated by Salmonella enterica subsp. enterica when the $25 \mathrm{~g}$ sample of caecal contents tested positive. The withinbatch positive caecal rate was established and categorised into three classes of Salmonella contamination: non-contaminated, moderately contaminated $(10 \%, 20 \%])$ and highly contaminated $(>20 \%)$.

A finishing batch was considered to be bacteriologically contaminated, i.e. shedding Salmonella, when only one environmental sample (pair of socks) tested positive for Salmonella. Similarly, finishing pigs from the same pen were considered to be housed in a Salmonella contaminated environment before leaving for the slaughterhouse when an environmental sample taken in the pen tested positive for Salmonella. Two dichotomous variables (contaminated versus non- contaminated) were therefore established: "bacteriological Salmonella status of the batch" and "bacteriological Salmonella status of the pen".

The individual serological status of the randomised pigs was established according to the cut-off of the indirect complete ELISA (cf. Sect. 2.5). The within-batch Salmonella seroprevalence was assessed by the proportion of seropositive pigs among the 30 pigs randomised in each room adjusted according to the sensitivity and specificity of the ELISA [26] with the Rogan-Gladen formula [29]. A three-level ordinal variable was defined from the tertiles of the adjusted prevalence distribution. The three classes included batches with less than 5\%, more than $5 \%$ but less than $25 \%$ and more than $25 \%$ of positive pigs, respectively.

The times recorded were used to calculate the holding time on the farm before loading, loading duration, duration of transport between the farm and the slaughterhouse, time in lairage at the slaughterhouse and fasting duration between feed withdrawal and slaughtering. These durations were coded categorically, according to the shape of the distributions or biological or regular cut-points. For the "fasting duration on the farm", a variable cut-off value was set at $16 \mathrm{~h}$. Total fasting duration should be at least $22 \mathrm{~h}$ from the farm to the stick according to good manufacturing practices recommended in France [19]. Taking into account the average transport time between farms and slaughterhouses, the mean loading and unloading time and the mean time in lairage at the slaughterhouse in France, a fasting time from 12 to $18 \mathrm{~h}$ should be observed on the farm [6]. The "time in lairage at the slaughterhouse" variable was categorised into three levels using two cutoff values: 3 and $6 \mathrm{~h}$. The first cut-off value defined a period of complete rest considered to be necessary for the pigs to recover from transport and associated handling [25, 40]. The second cut-off value corresponded to the average time in lairage observed in France [30]. 


\subsubsection{Statistical analysis}

Two analyses were carried out to assess the relationships between explanatory variables and Salmonella caecal status of the pigs at the individual and batch level.

In order to identify the risk factors for caecal contamination, the caecal results were first considered individually. The caecal results were related to individual serological results, bacteriological status of the pen and batch, and variables relative to the preharvest process in a random effects model, taking into account pen and batch clusters to match with the study design. In a first step, a bivariate analysis was carried out to check for the relationship between each explanatory variable and the individual caecal status by random effects logistic regression models with pen and batch random effects. Variables associated $(P<0.25)$ with the individual caecal status were selected. A multivariate random effects logistic regression model was then fitted with the explanatory variables selected. All random effects logistic models were performed using the GLIMMIX macro of SAS software [32].

In order to identify caecal contamination control points, caecal results were also analysed at the batch level. They were classified into three classes and considered in a cumulative logit model in order to determine key factors to switch from a higher to a lower contamination rate class. A twostage approach was performed. First, $\chi^{2}$ tests were performed to identify explanatory variables associated $(P<0.25)$ with the outcome variable. The variables retained were introduced into a cumulative logit model [20] to assess the relationships between explanatory variables and the caecal Salmonella status of the batch: (1) contaminated vs. non-contaminated; (2) highly contaminated vs. moderately or non-contaminated. The validity of the proportional odds assumption was checked by a $\chi^{2}$-Score test [2]. Bacteriological Salmonella status of the batch and the seropositive pig rate in the categories were highly correlated. In order to prevent final cumulative logit model from severe collinearity, these two explanatory variables were successively considered in two cumulative logit models. The cumulative logit models were performed using the LOGISTIC procedure of SAS software [32].

All logistic regressions were performed according to the method described by Hosmer and Lemeshow [13]. Backward stepwise logistic regression analyses were carried out to select explanatory variables and their first order interaction simultaneously and to adjust for confounding factors. All logistic regression models were obtained with all factors significant at $P<0.05$. Collinearity between the explanatory variables was assessed by bivariate analysis and model multicollinearity diagnostic analysis using the REG procedure of SAS software [32] according to the method recommended by Allison [1].

\section{RESULTS}

\subsection{Study sample and application of the protocol}

The general characteristics of the 101 farms involved in this study were similar to those of the groups taken as reference except for the average herd size, which was significantly higher than that of the national reference group. The mean age for slaughtering was 176.7 days $(\mathrm{SD}=10.9)$. Assessment of the bacteriological and serological Salmonella status was performed an average of 3.4 days $(\mathrm{SD}=2.3)$ before slaughtering. The fattening rooms studied were divided into 8.2 pens $(\mathrm{SD}=3.3)$ and housed an average of $129.5(\mathrm{SD}=57.3)$ finishing pigs. A total of 894 pairs of socks collected from the 832 pens were analysed. The mean surface of the fattening pen examined by one pair of socks was $11.88 \mathrm{~m}^{2}(\mathrm{SD}=8.06)$. The surface area sampled was not significantly different between positive and negative pens $(P>0.05)$. The number of pairs of socks 
used per room did not significantly influence the final status of the batch $(P>0.05)$.

A total of 1030 caecal content samples were taken on the slaughter line and were analysed for Salmonella with a mean number of 10.2 samples per batch $(\mathrm{SD}=0.8)$. The pigs sampled at the slaughterhouse were raised in 501 pens with one to ten pens represented per batch (average number of pens per batch $=5.2, \mathrm{SD}=1.6)$ and with one to seven pigs raised in the same pen (median $=2$, interquartile interval $=1$ ).

\subsection{Salmonella contamination and characteristics of the pre-slaughter processes studied}

Among the 101 batches studied, $37.6 \%$ (38/101) shed Salmonella enterica at the end of the finishing period. $14.5 \%$ (121/ 832) of the pens studied for Salmonella contamination tested positive. Eleven different Salmonella serovars were isolated from the pairs of socks analysed. The most prevalent serovars recovered in the finishing rooms were Derby and Typhimurium (Tab. I). One serovar was isolated in 33 of the 38 batches which tested positive (86.8\%) and two different serovars were simultaneously identified in the remaining five positive batches. The proportion of the pigs serologically examined, which presented COD values higher than the cut-off value of the indirect ELISA, was $24.3 \%$ (250/1030). The distribution of the within-batch Salmonella adjusted seroprevalence is shown in Figure 2. The distributions of fasting duration, transportation between farm and slaughterhouse and time in lairage at the slaughterhouse are shown in Figure 2.

Among the 1030 caecal samples analysed, $24.8 \%$ (256/1030) tested positive for Salmonella. At least one pig with positive caecal contents was encountered in $70.3 \%$ of the batches (71/101). The distribution of the within-batch positive caecal contents rate is shown in Figure 1. The three categories (defined according to the tertiles of the dis-
Table I. Isolation rates of Salmonella enterica subsp. enterica serovars identified on environmental samples performed by pairs of socks used in the pens of finishing pigs several days before leaving for the slaughterhouse and on contaminated caecal contents of these slaughtered pigs (101 farrow-to-finish pig farms, France, 2001).

\begin{tabular}{|c|c|c|}
\hline & \multicolumn{2}{|c|}{ Isolation rate on } \\
\hline & $\begin{array}{l}\text { Caecal contents } \\
\qquad(n=1030)^{\mathrm{a}}\end{array}$ & $\begin{array}{l}\text { Pair of socks } \\
\quad(n=894)^{\mathrm{b}}\end{array}$ \\
\hline$S$. Derby & 47.7 & 51.9 \\
\hline$S$. Typhimurium & 23.7 & 23.7 \\
\hline$S$. Infantis & 8.2 & 5.3 \\
\hline S. Brandenburg & 7.9 & 6.9 \\
\hline S. Panama & 3.2 & - \\
\hline S. Bredeney & 2.2 & 6.9 \\
\hline$S$. Anatum & 1.4 & 0.8 \\
\hline S. Kedougou & 0.7 & 1.5 \\
\hline S. Agona & 0.7 & 0.8 \\
\hline S. Mbandaka & 0.7 & 0.8 \\
\hline$S$. Livingstone & 0.7 & - \\
\hline$S$. London & 0.7 & - \\
\hline$S$. Enteritidis & 0.4 & - \\
\hline S. Montevideo & 0.4 & - \\
\hline$S$. Goldcoast & 0.4 & - \\
\hline S. Ohio & 0.4 & - \\
\hline$S$. Duisburg & 0.4 & - \\
\hline S. Napoli & 0.4 & - \\
\hline S. O:13,22,23 Hi & - & 0.8 \\
\hline S. Wien & - & 0.8 \\
\hline
\end{tabular}

a Caecal contents taken at slaughter.

b Faecal materials taken on the floor of pens on the farm.

tribution) included: all negative batches, batches with less than $20 \%$ of positive caecal samples and batches with more than $20 \%$ of positive caecal samples. Eighteen different Salmonella serovars were isolated from the caecal contents analysed. Derby and Typhimurium serovars were highly predominant (Tab. I). From one to six different serovars were identified per positive batch with a median of 1 (interquartile interval $=1)$. More than one serovar was identified in the caecal contents for $38.0 \%$ of the positive batches (27/71). 


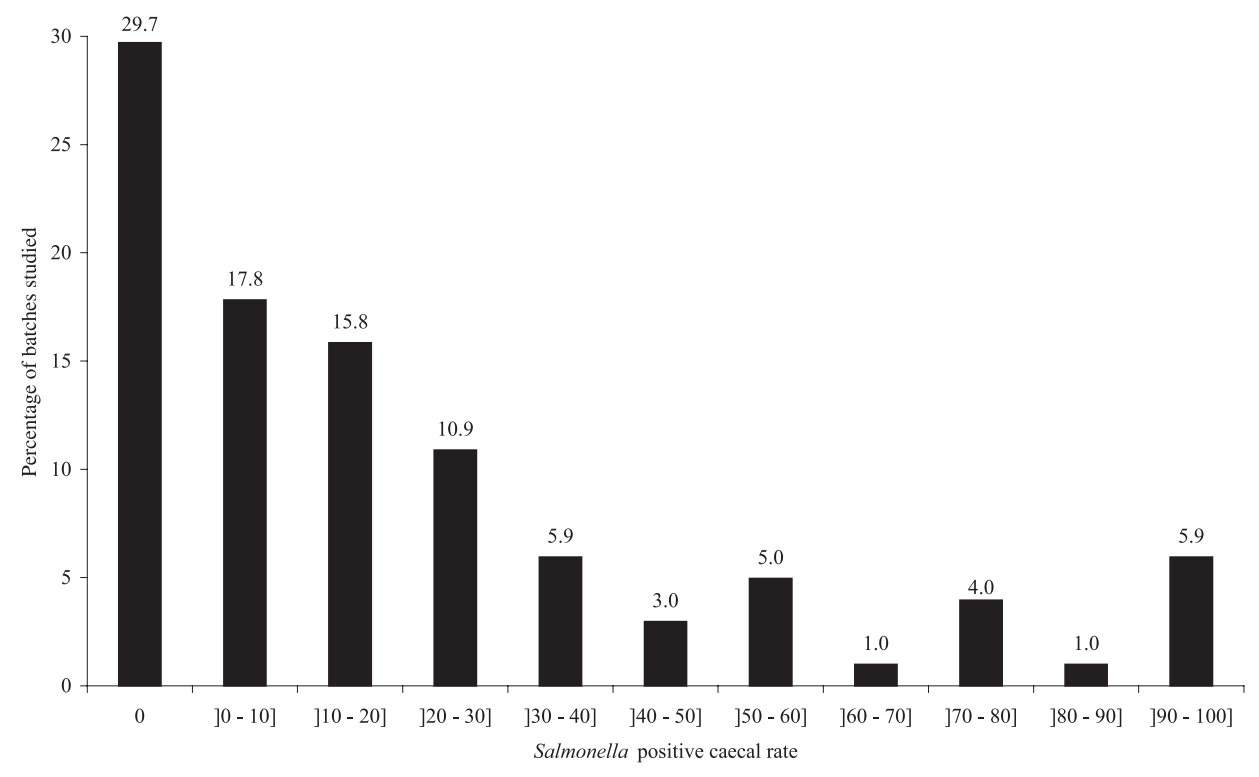

Figure 1. Salmonella positive caecal contamination rate at the batch level. $25 \mathrm{~g}$ of caecal contents taken on the slaughter line from 10 randomised slaughtered pigs (101 batches, France, 2001).

Among the 154 caecal contents sampled from pigs belonging to the Salmonella shedding batches, $115(74.7 \%)$ were contaminated with a serotype previously isolated on the farm. At the batch level, 31 batches presented both positive environmental and caecal samples. In four of them (12.9\%), the serotype(s) isolated on the farm and at the slaughterhouse were completely different.

\subsection{Logistic model performed on individual results}

Due to missing data, 940 pigs were included in this model. The putative factors related to the pre-harvest process and possibly linked to Salmonella contamination of the caecal contents of the pigs slaughtered are listed in Table II. The bacteriological Salmonella status of the pen was not significantly $(P>0.25)$ related to individual pig caecal contamination. However, the bacteriological Salmonella status of the batch was statistically associated to individual caecal contamination.

The significant $(P<0.05)$ batch and pen random effects were considered in the model. The factors associated with Salmonella caecal contamination in the final multivariate random effects logistic regression model are presented in Table III. A positive serological status of the pig and a positive bacteriological status of the batch both increased the risk of contamination of the caecal contents. Furthermore, time spent in lairage before slaughtering played a crucial role in caecal contamination.

\subsection{Logit cumulative models performed on batch results}

The two logit cumulative models were constructed with the Salmonella status of the batch at the end of the finishing period introduced either as the "seropositive rate" or as the assessment of "Salmonella shedding", respectively, which both remained in 

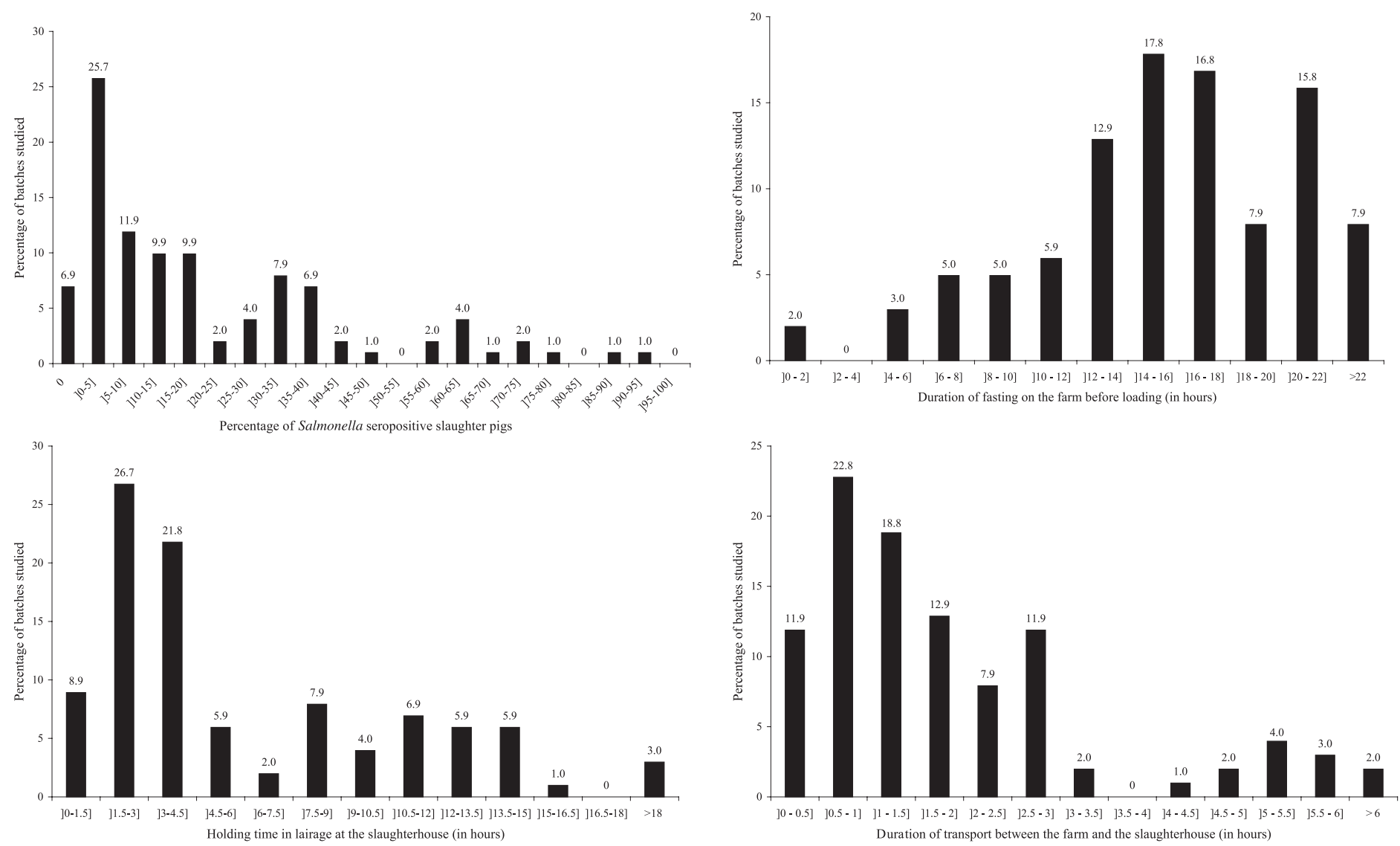

Figure 2. Distribution of explanatory variables for Salmonella caecal contamination: Salmonella seroprevalence in market-age pigs, fasting time on the farm, duration of transport, time in lairage (101 batches, 2001, France). 
Table II. Definition and distribution of collected explanatory variables of Salmonella caecal contamination rate (101 farrow-to-finish pig herds, France, 2001).

\begin{tabular}{|c|c|c|c|c|c|c|c|}
\hline \multirow{3}{*}{ Definition of the variables } & \multicolumn{4}{|c|}{ At the batch level $(n=101)$} & \multicolumn{3}{|c|}{ At the pig level $(n=940)$} \\
\hline & \multirow[t]{2}{*}{$\begin{array}{c}\% \text { of } \\
\text { batches }\end{array}$} & \multicolumn{2}{|c|}{$\begin{array}{c}\text { \% of positive } \\
\text { batches }^{\mathrm{b}, \mathrm{c}}\end{array}$} & \multirow[t]{2}{*}{$P^{f}$} & \multirow[t]{2}{*}{$\begin{array}{l}\% \text { of } \\
\text { pigs }^{\text {a }}\end{array}$} & \multirow[t]{2}{*}{$\begin{array}{l}\% \text { of posi- } \\
\text { tive pigs }\end{array}$} & \multirow[t]{2}{*}{$P^{g}$} \\
\hline & & Moderately ${ }^{\mathrm{d}}$ & Highlye $^{\mathrm{e}}$ & & & & \\
\hline $\begin{array}{l}\text { Salmonella shedding in the batch at the end } \\
\text { of the finishing period } \\
\text { Yes } \\
\text { No }\end{array}$ & $\begin{array}{l}37.6 \\
62.4\end{array}$ & $\begin{array}{l}29.0 \\
36.5\end{array}$ & $\begin{array}{l}52.6 \\
27.0\end{array}$ & 0.03 & $\begin{array}{c}39.3 \\
60.74\end{array}$ & $\begin{array}{l}38.8 \\
15.8\end{array}$ & 0.0002 \\
\hline $\begin{array}{l}\text { Salmonella shedding in the pen at the end } \\
\text { of the finishing period } \\
\text { Yes } \\
\text { No }\end{array}$ & - & - & - & - & $\begin{array}{l}14.9 \\
85.1\end{array}$ & $\begin{array}{l}50.0 \\
20.4\end{array}$ & 0.29 \\
\hline $\begin{array}{l}\text { Seropositivity rate against Salmonella } \\
\text { at the end of the finishing period } \\
\leq 5 \% \\
\quad 5-25 \% \\
>25 \%\end{array}$ & $\begin{array}{l}32.7 \\
33.7 \\
33.6\end{array}$ & $\begin{array}{l}24.24 \\
41.18 \\
35.29\end{array}$ & $\begin{array}{l}27.27 \\
32.35 \\
50.00\end{array}$ & 0.03 & - & - & - \\
\hline $\begin{array}{l}\text { Seropositivity against Salmonella at the end } \\
\text { of the finishing period } \\
\text { Yes } \\
\text { No }\end{array}$ & - & - & - & - & $\begin{array}{l}24.5 \\
75.5\end{array}$ & $\begin{array}{l}36.1 \\
21.1\end{array}$ & 0.01 \\
\hline $\begin{array}{l}\text { Type of feeding during the fattening phase } \\
\text { Wet } \\
\text { Dry }\end{array}$ & $\begin{array}{l}60.4 \\
39.6\end{array}$ & $\begin{array}{l}29.5 \\
40.0\end{array}$ & $\begin{array}{l}39.3 \\
32.5\end{array}$ & 0.55 & $\begin{array}{l}58.8 \\
41.2\end{array}$ & $\begin{array}{l}23.2 \\
27.1\end{array}$ & 0.55 \\
\hline $\begin{array}{l}\text { Fasting duration on the farm } \\
\quad>16 \mathrm{~h} \\
\leq 16 \mathrm{~h}\end{array}$ & $\begin{array}{l}47.6 \\
52.4\end{array}$ & $\begin{array}{l}30.6 \\
38.9\end{array}$ & $\begin{array}{l}28.6 \\
42.6\end{array}$ & 0.05 & $\begin{array}{l}47.9 \\
52.1\end{array}$ & $\begin{array}{l}20.0 \\
29.2\end{array}$ & 0.005 \\
\hline $\begin{array}{l}\text { Loading platform on the farm } \\
\text { Yes } \\
\text { No }\end{array}$ & $\begin{array}{l}61.4 \\
38.6\end{array}$ & $\begin{array}{l}33.9 \\
33.3\end{array}$ & $\begin{array}{l}38.7 \\
33.3\end{array}$ & 0.79 & $\begin{array}{l}59.7 \\
40.3\end{array}$ & $\begin{array}{l}25.1 \\
24.6\end{array}$ & 0.19 \\
\hline $\begin{array}{l}\text { Duration for loading the studied batch into } \\
\text { the truck } \\
\quad<20 \mathrm{~min} \\
\quad[20-40] \mathrm{min} \\
>40 \mathrm{~min}\end{array}$ & $\begin{array}{l}33.0 \\
34.0 \\
33.0\end{array}$ & $\begin{array}{l}38.2 \\
40.0 \\
26.5\end{array}$ & $\begin{array}{l}29.4 \\
37.1 \\
41.2\end{array}$ & 0.68 & $\begin{array}{l}30.3 \\
34.9 \\
34.8\end{array}$ & $\begin{array}{l}24.2 \\
22.0 \\
28.1\end{array}$ & 0.18 \\
\hline $\begin{array}{l}\text { Duration of transport between the farm and } \\
\text { the slaughterhouse } \\
\leq 1.5 \mathrm{~h} \\
\quad] 1.5-3] \mathrm{h} \\
>3 \mathrm{~h}\end{array}$ & $\begin{array}{l}54.4 \\
32.0 \\
13.6\end{array}$ & $\begin{array}{l}37.5 \\
36.4 \\
21.4\end{array}$ & $\begin{array}{l}28.6 \\
36.4 \\
64.3\end{array}$ & 0.04 & $\begin{array}{l}55.3 \\
31.7 \\
13.0\end{array}$ & $\begin{array}{l}20.0 \\
26.9 \\
40.2\end{array}$ & 0.14 \\
\hline $\begin{array}{l}\text { Holding pen in lairage washed with water } \\
\text { before loading } \\
\text { Yes } \\
\text { No }\end{array}$ & $\begin{array}{l}46.5 \\
53.5\end{array}$ & $\begin{array}{l}34.0 \\
33.3\end{array}$ & $\begin{array}{l}53.2 \\
22.2\end{array}$ & 0.0005 & $\begin{array}{l}45.0 \\
55.0\end{array}$ & $\begin{array}{l}34.6 \\
15.8\end{array}$ & $<0.0001$ \\
\hline $\begin{array}{l}\text { Time in lairage at the slaughterhouse } \\
\quad<3 \mathrm{~h} \\
3-6 \mathrm{~h} \\
>6 \mathrm{~h}\end{array}$ & $\begin{array}{l}35.9 \\
28.2 \\
35.9\end{array}$ & $\begin{array}{l}37.8 \\
37.9 \\
29.7\end{array}$ & $\begin{array}{l}13.5 \\
34.5 \\
59.5\end{array}$ & 0.0003 & $\begin{array}{l}37.7 \\
28.3 \\
34.0\end{array}$ & $\begin{array}{l}10.7 \\
27.1 \\
38.4\end{array}$ & $<0.0001$ \\
\hline $\begin{array}{l}\text { Season } \\
\text { Summer } \\
\text { Other seasons (spring and autumn) }\end{array}$ & $\begin{array}{l}41.6 \\
58.4\end{array}$ & $\begin{array}{l}25.4 \\
45.2\end{array}$ & $\begin{array}{l}40.7 \\
30.9\end{array}$ & 0.11 & $\begin{array}{l}58.9 \\
42.1\end{array}$ & $\begin{array}{l}26.4 \\
22.5\end{array}$ & 0.82 \\
\hline $\begin{array}{l}\text { Age at slaughtering } \\
\leq 170 \text { days } \\
170-180 \text { days } \\
>180 \text { days }\end{array}$ & $\begin{array}{l}32.0 \\
30.1 \\
37.9\end{array}$ & $\begin{array}{l}45.5 \\
32.3 \\
28.2\end{array}$ & $\begin{array}{l}30.3 \\
25.8 \\
48.7\end{array}$ & 0.21 & $\begin{array}{l}36.7 \\
31.2 \\
32.1\end{array}$ & $\begin{array}{l}23.5 \\
18.8 \\
32.1\end{array}$ & 0.19 \\
\hline
\end{tabular}

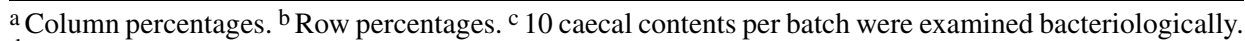
${ }^{d}$ Batches with less than $20 \%$ of caecal contents examined tested positive. ${ }^{\mathrm{e}}$ Batches with more than $20 \%$ of caecal contents examined tested positive. ${ }^{\mathrm{f}} P$-value of the $\chi^{2}$-test performed with caecal contents contamination rate in three categories $(0 \% ;] 0 \%-20 \%] ;>20 \%)$. g $P$-value from a univariate logistic model with $\mathrm{t}$ batch and pen random effects, performed with GLIMMIX procedure. 
Table III. The final random effects logistic regression model for risk factors for individual Salmonella caecal contamination at slaughter (940 slaughter pigs, France, 2001).

\begin{tabular}{lcc}
\hline \multirow{2}{*}{ Variables } & \multicolumn{2}{c}{ Random effects logistic model ${ }^{\text {a }}$} \\
\cline { 2 - 3 } & OR & $95 \% \mathrm{CI}$ \\
\hline $\begin{array}{l}\text { Salmonella seroconversion at the end of the finishing period } \\
\quad \text { No }\end{array}$ & 1 & - \\
$\quad$ Yes & 1.5 & $1.0-2.3$ \\
Salmonella shedding in the batch at the end of the finishing & & \\
period & 1 & - \\
$\quad$ No & 4.9 & $2.0-11.8$ \\
$\quad$ Yes & & - \\
Time in lairage at the slaughterhouse & 1 & $1.1-9.9$ \\
$\quad<3 \mathrm{~h}$ & 3.3 & $4.7-36.1$ \\
$\quad 3-6 \mathrm{~h}$ & 13.1 & \\
$>6 \mathrm{~h}$ &
\end{tabular}

a Estimates and standard errors were assessed using a mixed model with pen and farm random effects. Intercept $=-2.3$; deviance $=394.7$, residual variance $=0.4$, batch variance $=3.1$, pen variance $=2.4$.

the two final models $(P<0.05)$. The other explanatory variable retained $(P<0.05)$ in the two models was "time spent in lairage at the slaughterhouse". The $\chi^{2}$-Score test did not reject the proportional odds assumption for the two models (Tab. IV). It is therefore assumed that the relationship between the explanatory variables and caecal contamination rate is independent of the cut-off value considered to dichotomise the outcome. Log odds-ratio across the two cut-off points defined $(0 \% ; 20 \%)$ can therefore be considered to be identical. The odds ratio given in Table IV can be interpreted as the effect of the explanatory variables on the odds of being in a higher rather than a lower category.

Considering model 1 , the odds of being in a higher category (i.e. in a higher caecal contamination rate category) for a Salmonella shedding batch is 2.6-fold higher than the odds for a non-shedding batch. Considering model 2 , a batch characterised by more than $25 \%$ of seropositive slaughter pigs has a more than fourfold higher odds of being in a higher category than in a lower category compared to a batch with a seropositive rate lower than $5 \%$. In the two mod- els, time spent in lairage greatly increased the odds of having a higher caecal contamination rate. The second intercept of model 1 $(-2.09)$ is the predicted log-odds of being in a highly contaminated category rather than in the moderately or non-contaminated categories, for a batch which did not shed Salmonella and which waited for less than three hours before slaughtering. Batches were more than eight times as likely to be in the moderately or non-contaminated categories than in the highly contaminated category when they did not shed on the farm and when they waited for less than three hours before slaughtering. Similarly, batches were more than 13 times as likely to be in the moderately or non-contaminated categories than in the highly contaminated category when the seropositive rate was less than 5\% and time spent in lairage was less than three hours.

\section{DISCUSSION}

The previous studies investigating the relationships between the pre-slaughter process and Salmonella digestive tract contamination on the slaughter line have mainly 
Table IV. Logit cumulative models performed on batch results for risk factors for Salmonella caecal contamination (101 batches, France, 2001).

\begin{tabular}{ll}
\hline Intercept / Variables & Cumulative logit model \\
& OR $95 \%$ CI \\
\hline
\end{tabular}

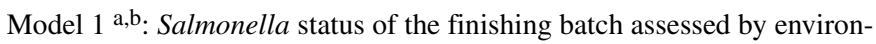
mental bacteriology

Intercept "contaminated vs. non-contaminated" $=-0.32(\mathrm{se}=0.36)$;

$P=0.36$

Intercept "highly contaminated vs. moderately or non-contaminated" = -2.09 (se $=0.42) ; P<0.0001$

Salmonella shedding at the end of the finishing period

No

Yes

Time in lairage at the slaughterhouse
$<3 \mathrm{~h}$
$3-6 \mathrm{~h}$
$1-$
$>6 \mathrm{~h}$
$2.8 \quad 1.1-7.3$
$8.1 \quad 3.1-21.2$

Model $2^{\mathrm{c}, \mathrm{d}}$ : Salmonella status of the finishing batch assessed by serology (indirect ELISA)

Intercept "contaminated vs. non-contaminated" $=-0.78($ se $=0.44)$;

$P=0.08$

Intercept "highly contaminated vs. moderately or non-contaminated" =

-2.59 (se $=0.52) ; P<0.0001$

Seropositivity rate against Salmonella at the end of the finishing period

$$
\begin{aligned}
& \leq 5 \% \\
& 5-25 \% \\
& >25 \%
\end{aligned}
$$$$
1-
$$

Time in lairage at the slaughterhouse
$<3 \mathrm{~h}$
$3-6 \mathrm{~h}$
$>6 \mathrm{~h}$

\footnotetext{
a Score test of the proportional odds assumption: $\chi^{2}=0.49$ (d.f. $=3, P=0.92$ ).

b Likelihood ratio test: $\chi^{2}=26.8$ (d.f. $=3, P<0.0001$ ).

${ }^{c}$ Score test of the proportional odds assumption: $\chi^{2}=2.2$ (d.f. $\left.=4, P=0.70\right)$.

d Likelihood ratio test: $\chi^{2}=30.7$ (d.f. $=4, P<0.0001$ ).
}

been experimental or molecular epidemiological studies. Field observational studies are needed in order to confirm the role of the factors suspected to be involved throughout the pre-slaughter process. The current survey was designed for this purpose. Due to the practical constraints of the protocol, the farm sample studied could not be a random sample. However, it was found retrospectively that the technical profile of this sample was similar to that of the regional and national reference groups of pig farms except for the average herd size, which was significantly higher than that of the national 
reference group. The farm and slaughterhouse routines were strictly respected in order to limit the intervention bias. Epidemiological data were recorded directly from the persons concerned with a limited delay. The double identification by ear tag and shoulder tattoo of the pigs and subsequent carcasses should have limited the errors of identification of the viscera.

In this study, Salmonella shedding by market-age pig batches was assessed by environmental examination. In subclinically infected herds, slaughter pigs have a chronic and silent infection with only intermittent and low levels of Salmonella excretion [24, 42]. Examination of individual faecal samples on a sample of pigs therefore constitutes a poorly sensitive method [12]. Similarly, environmental swabbing in broiler flocks was found to be more sensitive than individual coprology performed on a sample of animals [34]. Since ubiquitous Salmonella are resistant in the environment of the pigs, pen samples representing several individuals (between 12 to 20) appeared to be an appropriate way to assess the microbiological status of finishing pig pens or batches.

The pig herd Salmonella contamination rate assessed in this study was $37.6 \%$. This result should be interpreted cautiously, since the studied sample was not randomised from the French farrow-to-finish pig herd population. Previously published studies concerning Salmonella enterica contamination of pig herds assessed by environmental samples are relatively rare. The pig herd Salmonella contamination rates reported in three different studies were $23.7 \%$ [39], $21 \%$ [35], $10.1 \%$ [36]. Since the type of sample used in these studies was pooled faecal samples, it is therefore difficult to compare these data with the results of our study, obtained using a specific device. According to Van der Wolf et al. [39], the prevalence observed in their study underestimated the "true" prevalence of Salmonella in pigs in The Netherlands. The differences in herd sampling and in the sensitivity of the environmental sampling methods used could explain the different rates observed in the present study and reported in the literature.

In this study, the Salmonella status of the pigs at the slaughterhouse was assessed using caecal contents rather than gut-associated lymph nodes or carcass surface contamination. Swanenburg et al. [37] reported that the slaughter line was the most important source of Salmonella contamination of carcasses. Therefore, carcass surface contamination is likely to reflect the hygienic quality of in-plant practices and may not be a useful measure of pre-slaughter prevalence [38]. Gut-associated lymph nodes have been shown to be less sensitive samples than caecal contents in several studies [21, 24]. In a previous study performed on 160 pigs at the slaughterhouse, $25 \%$ of the pigs carried Salmonella (40/160) in the ileocaecal lymph nodes, whereas 40\% (63/ 160) of the same pigs harboured the bacteria in the caecal contents [3].

The proportion of caecal contents, which tested positive for Salmonella, was 24.8\% (256/1030). Similar contamination rates have been reported in the United States with $21.2 \%$ (58/273) of caecal contents contaminated [15]. However, these authors analysed $10 \mathrm{~g}$ of caecal contents, whereas $25 \mathrm{~g}$ were collected and tested in the present study.

The variability of the Salmonella serovars isolated in the study increased between the farms and the slaughterhouses. Nine serovars not found in faecal material collected on the farm were identified in the caecal contents at the slaughterhouse. The mean number of serovars isolated per batch also increased between the farm and the slaughterhouse. These phenomena have been previously reported by Hurd et al. [15, 16] and McKean et al. [21], who hypothesised cross-contamination in lairage.

The type of feeding and the presence of a loading platform were the only two variables related to the farm equipment or management system which were analysed and taken into account. Differences in the digestion process between wet and dry feeds 
have been previously observed [19]. Stress induced at loading (which is related to the use of a loading platform or not) might increase Salmonella endogenous dissemination [33]. Other variables related to the on-farm management characteristics, such as the type of rearing facilities, hygiene routines, etc. were not taken into account in this study. These variables are more closely related to the Salmonella status at marketage than to the outcome variable "caecal contents contamination at the slaughterhouse". Introducing distant or indirect etiological factors and treating them as equal in proximity to the outcome is known to allow inadequate stepwise multiple regression modelling [41].

The densities of the pigs in the lorries and in the holding pens in lairage have been reported in the literature to be a potential risk factor for increasing Salmonella prevalence between the farm and the slaughterhouse [40]. However, lorry drivers were not questioned about pig density in the lorries and these data were not recorded in this study due to a lack of expected variability. Several studies carried out in France during recent years have reported an average density in lorries of 2.5 pigs (average live weight: $107 \mathrm{~kg}) / \mathrm{m}^{2}$ with a coefficient of variation of $5.4 \%[5,7,8]$. Densities in the holding pens in lairage could not be recorded due to technical and logistical difficulties at the slaughterhouses. For similar reasons, Salmonella contamination of the holding pens in lairage was not assessed. However, Salmonella contamination in lairage is considered to be widespread. Rostagno et al. [31] in the USA found 24 out of 24 samples contaminated in lairage pens during a working day. In The Netherlands, Swanenburg et al. [38] isolated Salmonella in $70 \%$ to $90 \%$ of the environmental swab samples taken in lairage when pigs were present. In the slaughterhouses studied by Swanenburg et al. [38] and in those involved in the present study, the lairage was washed at the end of the working day without cleaning and disinfection. In the present study, on the contrary to all expectations, the analysis of the batches of pigs loaded in lairage after washing revealed a higher contamination rate of caecal contents than in the other batches. The batches loaded in a washed lairage were more likely to have waited longer in lairage ("time spent in lairage" $x$ "loading in a washed lairage": $\chi^{2}=58.5, P<$ 0.0001 - data not shown). They were commonly unloaded in the evening and slaughtered the next morning. The "time spent in lairage" variable, which was most strongly related to the outcome variable, was retained in the model.

At the individual level, a random effects logistic regression model was fitted to explain the contamination of the caecal contents by Salmonella status at the end of the finishing period and the pre-slaughter process. Since all pigs sampled could not be assumed to be independent, a mixed logistic model was fitted taking into account the pens and batches clusters. Pigs fattened in the same batch were submitted to similar rearing (feeding, hygiene, climate, etc.) and preharvest conditions (time in lairage on the farm and at the slaughterhouse, duration of transport, etc.). Moreover, pigs reared in the same batches were mixed during lairage on the farm and at the slaughterhouse before slaughtering. A pen random effect was also introduced in the model because pigs fattened in the same pen were submitted to the same residual environmental Salmonella contamination and oro-faecal contamination was obviously possible between pen mates. It has been previously described that pig Salmonella status can differ considerably between two pens in the same fattening room $[3,9,12]$. A pen cluster level was also identified when studying serological responses to Salmonella in a previous study [3].

Modelling at the individual level assessed the effect of Salmonella status of the pigs and the batches at the end of the finishing period on caecal contamination. Belonging to a Salmonella shedding batch or presenting seroconversion for Salmonella both increased the risk of contaminated caecal contents. This result is consistent with the high isolation 
rate of the same serovar between the farm and the slaughterhouse observed in the present study. Moreover, a link between Salmonella shedding on the farm and caecal contamination has already been identified. A relationship between Salmonella isolates on the farm and the isolates found on the carcasses was reported in a molecular epidemiological study [37]. Nevertheless, other authors did not report any individual correlation between serology or faecal examinations on the farm and contamination of the caecal contents at the slaughterhouse [10]. However, being reared in a fattening pen with a positive bacteriological Salmonella status was not associated with the caecal contamination. The different effect of the bacteriological Salmonella status of the pen and of the batch might be related to the effect of the mixing of pigs during lairage, first on the farm and then at the slaughterhouse. Pigs reared in a negative pen may be contaminated by contact with Salmonella shedders of the same batch.

The effect of the time spent in lairage on Salmonella caecal contamination was identified as a crucial risk factor by the modelling at the individual level. The longer the time spent by the pigs in lairage, the higher was the risk for caecal contamination. The effect of the time spent in lairage can be interpreted as a cross-contamination stage in holding pens with contaminated faecal materials shed by previous batches or pen mates of the same batch. Bacteriological studies, based on serotyping or molecular identification, have established a relation between Salmonella strains found in caecal contents and those isolated in lairage [31, 37]. These observations are in accordance with experiments which demonstrated the feasibility of rapid contamination of pigs by the environment $[11,14]$. Moreover, the lairage environment has been frequently found to be positive during the working day $[31,38]$. Whenever pigs waited in lairage at the slaughterhouse, an increase in the contamination rate was shown by studies which compared slaughtering on the farm and at the slaughterhouse $[15,16]$. A study carried out in 1987 also showed that contamination increased with the time spent in lairage, but the times compared ( $18 \mathrm{~h}, 42 \mathrm{~h}$ and $66 \mathrm{~h})$ are very different from current reality [22]. Three hours in lairage was the reference level considered in the present study. It is considered to be the time required before slaughtering in terms of animal welfare and meat quality $[25,40]$. Nevertheless, crosscontamination has been shown to occur within two hours [14].

Other factors related to the pre-harvest process have been reported in the literature to be associated with caecal contamination. The protective effect of a fasting time on the farm longer than $16 \mathrm{~h}$ was observed by Isaacson et al. [17]. A fasting time greater than $16 \mathrm{~h}$ did not remain in the final mixed logistic model, although it was found to be protective on univariate analysis. The transport effect was previously thought to be moderate. It was found to increase Salmonella caecal contamination only when the transported pigs remained on feed [17]. When tracing Salmonella serotypes isolated from farms, trucks, holding pens and caecal contents, Swanenburg et al. [37] considered that transport was a minor source of Salmonella contamination. The duration of transport did not remain in the final mixed logistic model. The effect of factors, such as transport or duration of fasting on the farm, cannot be excluded. In this study, they did not appear to be significant with respect to the time spent in lairage and Salmonella status on the farm.

The model fitted at the individual level was performed for analytical purposes. However, the determination of key points of a Salmonella risk management programme (that must be devised and applied at the batch or farm level) and quantification of their relative weights would require classification of the batches according to their Salmonella caecal contamination rate. A cumulative logit model was therefore fitted to take into account the ordering of the three classes of batches performed. Moreover, the cumulative model focuses on extreme 
categories ("absence of caecal contamination" and "high caecal contamination"), which are of special interest from the risk management viewpoint to propose factors/ points on which a control programme should focus in order to preserve a non-contaminated status or to move from a highly contaminated status to a less contaminated status. However, since the proportional odds assumption was not rejected, the logit cumulative models suggested that the risk factors identified had the same impact on batches regardless of the caecal contamination rate considered. Therefore, recommended control measures should be considered more as guidelines for good manufacturing hygiene practices to be applied as standard practice, rather than control measures specifically concerning one class of batch.

Like the model fitted at the individual level, modelling at the batch level identified the time spent in lairage at the slaughterhouse and the Salmonella status of the batch as risk factors for caecal contamination. The influence of the serological batch status has already been reported in the literature. A significant correlation between herd seroprevalence and bacteriological findings in the caecal contents was described in United Kingdom [10]. Quirke et al. [27] also showed that, for a pig, belonging to a herd with more than $32 \%$ of seropositive animals was a significant risk factor for Salmonella caecal contamination at the slaughterhouse.

The results of this study emphasise the need for control measures at both the farm and the slaughterhouse. On the farm, infection and shedding should be reduced by means of identification and control of risk factors for Salmonella shedding and/or Salmonella seroconversion. At the slaughterhouse, control measures should be implemented to reduce the time spent in lairage before slaughtering or to limit cross-contamination in lairage. Frequent and effective cleaning and disinfection of holding pens, more suitable floors in lairage (slats) reducing faecal contacts and, when possible, seg- regated slaughtering should be implemented in the near future.

\section{ACKNOWLEDGEMENTS}

The authors gratefully acknowledge the production and feed companies, the investigators, the farmers and the slaughterhouses for their cooperation in this project, $\mathrm{Mr}$ J. Erauso, Mr Y. Hascoet, Ms C. Fablet, Mr J.-P. Jolly, Mr E. Eveno, Ms C. Houdayer, Mr V. Porphyre, Mr N. Rose for their help. This project was financially supported by the Food Safety Department of the French Ministry of Agriculture, Food, Fisheries and Rural Affairs.

\section{REFERENCES}

[1] Allison P.D., Logistic regression using the SAS system. Theory and application, SAS Institute and Wiley, Cary, NC, USA, 2001.

[2] Ananth C.V., Kleinbaum D.G., Regression models for ordinal responses: a review of methods and applications, Int. J. Epidemiol. 26 (1997) 1323-1333.

[3] Belœil P.-A., Chauvin C., Proux K., Rose N., Queguiner S., Eveno E., Houdayer C., Rose V., Fravalo P., Madec F., Longitudinal serological responses to Salmonella enterica of growing pigs in a subclinically infected herd, Prev. Vet. Med. 60 (2003) 207-226.

[4] Berends B.R., Urlings H.A.P., Snijders J.M.A., Knapen F.V., Identification and quantification of risk factors in animal management and transport regarding Salmonella spp. in pigs, Int. J. Food Microbiol. 30 (1996) 37-53.

[5] Chevillon P., Densités et conditions de transport des porcs en France, Institut Technique du Porc, Paris, 1995.

[6] Chevillon P., Mortality rate during pig transport and welfare of pigs, Techniporc 21 (1998) 13-18 (in French).

[7] Chevillon P., Rousseau P., Welfare of finishing pigs during loading and transport in winter: effect of cover or the closing of ventilation flaps on the left side, Techniporc 22 (1999) 19-23 (in French).

[8] Colleu T., Chevillon P., Rousseau P., Enquête sur les niveaux et les évolutions des paramètres d'ambiance en cours de transport, Techniporc 21 (1998) 27-31. 
[9] Dahl J., Wingstrand A., Nielsen B., Baggesen D.L., Elimination of Salmonella Typhimurium infection by the strategic movement of pigs, Vet. Rec. 28 (1997) 679-681.

[10] Davies R.H., Health P.J., Coxon S.M., Sayers A.R., Evaluation of the use of pooled serum, pooled muscle tissue fluid (meat juice) and pooled faeces for monitoring pig herds for $\mathrm{Sal}$ monella, J. Appl. Microbiol. 95 (2003) 10161025 .

[11] Fedorka-Cray P.J., Kelley L.C., Stabel T.J., Gray J.T., Laufer J.A., Alternate routes of invasion may affect pathogenesis of Salmonella Typhimurium in swine, Infect. Immun. 63 (1995) 2658-2664.

[12] Fravalo P., Rose V., Eveno E., Salvat G., Madec F., Bacteriological assessment of the Salmonella status of market-age pigs: evaluation from rearing facilities to slaughter, Journées de la Recherche Porcine 31 (1999) 383 389 (in French).

[13] Hosmer D.W., Lemeshow S., Applied Logistic regression, Wiley, New York, 1989, p. 307.

[14] Hurd H.S., Gailey J.K., McKean J.D., Rostagno M.H., Rapid infection in market-weight swine following exposure to a Salmonella Typhimurium-contaminated environment, Am. J. Vet. Res. 62 (2001) 1194-1197.

[15] Hurd H.S., McKean J.D., Wesley I.V., Karriker L.A., The effect of lairage on Salmonella isolation from market swine, J. Food Prot. 64 (2001) 939-944.

[16] Hurd H.S., McKean J.D., Griffith R.W., Wesley I.V., Rostagno M.H., Salmonella enterica infections in market swine with and without transport and holding, Appl. Environ. Microbiol. 68 (2002) 2376-2381.

[17] Isaacson R.E., Firkins L.D., Weigel R.M., Zuckermann F.A., Di Pietro J.A., Effect of transportation and feed withdrawal on shedding of Salmonella Typhimurium among experimentally infected pigs, Am. J. Vet. Res. 60 (1999) 1155-1158.

[18] Institut Technique du Porc, Le porc par les chiffres, ITP Éditions, Paris, 2000

[19] Magras C., Delaunay I., Beneteau E., What is the ideal fasting time before slaughter to optimise carcass quality? Slaughterhouse observations, Journées de la Recherche Porcine 32 (2000) 351-356 (in French).

[20] McCullagh P., Regression models for ordinal data (with discussion), J. R. Stat. Soc. Ser. B 42 (1980) 109-142.

[21] McKean J.D., Hurd H.S., Larsen S., Rostagno M., Griffith R., Wesley I., Impact of commercial pre-harvest processes on the prevalence of
Salmonella enterica in culled sows, Berl. Munch. Tierarztl. Wochenschr. 114 (2001) 353-355.

[22] Morgan I.R., Krautil F.L., Craven J.A., Effect of time in lairage on caecal and carcass Salmonella contamination of slaughter pigs, Epidemiol. Infect. 98 (1987) 323-330.

[23] Morrow W.E.M., See M.T., Eisemann J.H., Davies P.R., Zering K., Effect of withdrawal feed from swine on meat quality and prevalence of Salmonella colonisation at slaughter, J. Am. Vet. Med. Assoc. 220 (2002) 497-502.

[24] Nielsen B., Baggesen D., BagerF., Haugegaard J., Lind P., The serological response to Salmonella serovars Typhimurium and Infantis in experimentally infected pigs. The time course followed with an indirect anti-LPS ELISA and bacteriological examinations, Vet. Microbiol. 47 (1995) 205-218.

[25] Perez M.P., Palacio J., Santolaria M.P., Acena M.C., Chacon G., Verde M.T., Calvo J.H., Zaragoza M.P., Gascon M., Garcia-Belenguer S., Influence of lairage time on some welfare and meat quality parameters in pigs, Vet. Res. 33 (2002) 239-250.

[26] Proux K., Houdayer C., Humbert F., Cariolet R., Rose V., Eveno E., Madec F., Development of a complete ELISA using Salmonella lipopolysaccharide of various serogroups allowing to detect all infected pigs, Vet. Res. 31 (2000) 481-490.

[27] Quirke A.M., Leonard N., Kelly G., Egan J., Lynch P.B., Rowe T., Quinn P.J., Prevalence of Salmonella serotypes on pig carcasses from high- and low-risk herds slaughtered in three abattoirs, Berl. Munch. Tierarztl. Wochenschr. 114 (2001) 360-362.

[28] Rajkowski K.T., Eblen S., Laubauch C., Efficacy of washing and sanitizing trailers used from swine transport in reduction of Salmonella and Escherichia coli, J. Food Prot. 61 (1998) 31-35.

[29] Rogan W.J., Gladen B., Estimating prevalence from the results of a screening test, Am. J. Epidemiol. 107 (1978) 71-76.

[30] Rossel R., Le Roux A., Minvielle B., Contamination en salmonelles des camions de transport de porcs charcutiers et des porcheries d'attente, Techniporc 25 (2002) 27-31.

[31] Rostagno M.H., Hurd H.S., McKean J.D., Ziemer C.J., Gailey J.K., Leite R.C., Preslaughter holding environment in pork plants is highly contaminated with Salmonella enterica, Appl. Environ. Microbiol. 69 (2003) 4489-4494. 
[32] SAS Institute, SAS/STAT User's Guide, Version 8, SAS Institute Inc., Cary, NC, USA, 1999.

[33] Seidler T., Alter T., Krüger M., Fehlhaber K., Transport stress - consequences for bacterial translocation, endogenous contamination and bactericidal activity of serum of slaughter pigs, Berl. Munch. Tierarztl. Wochenschr. 114 (2001) 1-3.

[34] Skov M.N., Carstensen B., Tornoe N., Madsen M., Evaluation of sampling methods for the detection of Salmonella in broiler flocks, J. Appl. Microbiol. 86 (1999) 695-700.

[35] Stege H., Christensen J., Nielsen J.P., Baggesen D.L., Enøe C., Willeberg P., Prevalence of subclinical Salmonella enterica infection in Danish finishing pig herds, Prev. Vet. Med. 44 (2000) 175-188.

[36] Stege H., Jensen T.K., Møller K., Bækbo P., Jorsal S.E., Prevalence of intestinal pathogens in Danish finishing pig herds, Prev. Vet. Med. 46 (2000) 279-292.

[37] Swanenburg M., Berends B.R., Urlings H.A.P., Snijders J.M.A., van Knapen F., Epidemiological investigations into the sources of Salmonella contamination of pork, Berl. Munch. Tierarztl. Wochenschr. 114 (2001) 356-359.
[38] Swanenburg M., Urlings H.A.P., Keuzenkamp D.A., Snijders J.M.A., Salmonella in the lairage of pig slaughterhouses, J. Food Prot. 64 (2001) $12-16$.

[39] Van der Wolf P.J., Bongers J.H., Elbers A.R., Franssen F.M., Hunneman W.A., van Exsel A.C., Tielen M.J., Salmonella infections in finishing pigs in The Netherlands: bacteriological herd prevalence, serogroup and antibiotic resistance of isolates and risk factors for infections, Vet. Microbiol. 67 (1999) 263275 .

[40] Warriss P.D., Brown S.N., Edwards J.E., Anil M.H., Fordham D.P., Time in lairage needed by pigs to recover from the stress of transport, Vet. Rec. 131 (1992) 194-196.

[41] Weitkunat R., Wildner M., Exploratory causal modeling in epidemiology: are factors created equal? J. Clin. Epidemiol. 55 (2002) 436-444.

[42] Wilcock B.P., Schwartz K.J., Salmonellosis, in: Leman A., Straw B.E., Mengeling W.L., d'Allaire S., Taylor D.J. (Eds.), Diseases of swine, Iowa State University Press, Ames, 1992, pp. 570-583.

[43] Williams L.P. Jr., Newell K.W., Salmonella excretion in joy riding pigs, Am. J. Public Health Nations Health 60 (1970) 926-929. 